\section{Engelhardt e a Saúde Pública: Cobertura ou acesso universal?}

\section{Gualberto, João Marcos}

Mestrando - Programa de Pós-graduação em Bioética UnB.E-mail: gualberto781@gmail.com.

\section{Oliveira, Marília Aires de}

Mestranda - Programa de Pós-graduação em Bioética UnB.E-mail: aires.marilia@gmail.com

PALAVRAS-CHAVE: Engelhardt; saúde pública; recursos; Bioética

Introdução: Engelhardt é um importante autor da bioética, principalmente em virtude de suas ideias sobre a autonomia/consentimento dos indivíduos, os amigos morais e o conceito de comunidades. Porém, foi no campo da saúde pública que este autor causou grande repercussão ao defender a cobertura universal de saúde. Segundo esta ideia, cada indivíduo teria acesso ao tipo de atendimento em saúde proporcional ao que pudesse ou quisesse comprar(1). Por outro lado, no âmbito de um sistema de saúde de acesso universal, como é o Sistema Único de Saúde (SUS), é importante conciliar a escassez de recursos públicos e a oferta de saúde gratuita, e esta dificuldade vem valorizando paulatinamente as ideias de Engelhardt. Desta maneira este trabalho tem como objetivo discorrer sobre o pensamento de Engelhardt sobre a saúde pública e tentar apontar como tais ideias tem motivado as propostas de mudança do sistema de saúde público brasileiro. Metodologia: Trata-se de pesquisa bibliográfica em bancos de dados e bibliotecas virtuais; de artigos publicados na íntegra e de livros da área da Bioética nos idiomas português e inglês. Resultado: Para Engelhardt a sociedade deveria ser dividida entre os que são atendidos pelos melhores planos de saúde e os atendidos pelos planos básicos, dependendo das condições financeiras de cada um (2). Desta maneira o sistema de saúde não seria responsabilidade do Estado (3) . Tal visão descarta a vulnerabilidade de grande parte da população do Brasil, negando a ela a oportunidade de ter uma vida digna através de um adequado atendimento de saúde (4). Entretanto, a escassez de recursos designados à saúde pública no Brasil e a consequente precarização dos serviços ofertados, vem disseminando a ideia de substituir o SUS (com sua oferta de acesso amplo à saúde), pelos planos de saúde populares (com suas coberturas conforme o que o indivíduo possa pagar). Tal proposta dialoga com o discurso do autor em questão. Conclusão: A tendência brasileira atual de desmantelamento do SUS, e a proposta de oferta de planos de saúdes com cobertura proporcional ao preço dos mesmos vem se intensificando. Ela é motivada pela escassez de recursos destinados aos serviços de saúde e a sua consequente redução de qualidade. Entretanto, a utopia da melhoria do acesso através dos planos de saúde, tal como proposto por Engelhardt, esconde a total desconsideração pela vulnerabilidade populacional. Desta maneira, os mais ricos teriam planos de saúde mais completos, enquanto que aos mais pobres caberia os planos mais básicos e com pouca cobertura. Caso tal proposta seja aprovada, as iniquidades no Brasil serão mantidas e as desigualdades sociais no campo da saúde se perpetuarão fazendo com que os mais vulneráveis sejam os mais afetados.

AGRADECIMENTOS: Agradecemos ao Professor Doutor Volnei Garrafa, por todos os ensinamentos ofertados, e a Universidade de Brasília, pela oferta de programas de excelência em pós-graduação.

\section{REFERÊNCIAS}

[1] ENGELHARDT HT. Fundamentos da Bioética. 5a edição. Edições Loyola; 1996. 518 p.

[2] ENGELHARDT HT. Bioética Global. Paulinas Editora; 2012. $493 \mathrm{p}$.

[3] ENGELHARDT HT, RIE MA. Intensive care units, scarce resources, and conflicting principles of justice. Jama. 1986;255(9):1159-64.

[4] LORENZO, C. (2006). Vulnerabilidade em saúde pública: implicações para as políticas públicas. Revista Brasileira de Bioética. 2006; 2(3): 299-312. 